\title{
Review of the Research on the Fiscal Risk of PPP Model of Municipal Infrastructure
}

\author{
Chen Du \\ School of economics and finance of WuHan Business University, WuHan, HuBei, China
}

252564120@qq.com

Keywords: Infrastructure, PPP model, Financial risk.

Abstract. This paper summarizes the relevant research results of financial risk of Municipal Infrastructure PPP model in China and abroad in recent years, evaluates these research results, and looks forward to the future research direction of Municipal Infrastructure PPP model in China.

\section{A review of foreign studies}

Foreign research on the financial risk of PPP mode focuses on the financial risk caused by the project failure caused by the internal mechanism of PPP. Hana polackova (2002) is the representative of financial risk research, her financial risk matrix is very helpful to analyze and evaluate the government debt and has changed people's views on the government debt and expanded the research scope of financial risk. Some scholars believe that the financial risk may come from the investment risk of the government in infrastructure to a large extent. Timothy. Irwin, Michael. Klein, Guillermo. E. Perry and mateen. Thobani (1999) discussed the risks of private investment in infrastructure to the government, and then summarized how to manage these risks. Hemming Richard (2006) believes that the government's contingent and implicit debts to PPP projects cannot be ignored, which may affect the overall operation of the financial system. Darrin Grimsey (2002) classifies the risks that PPP projects will face in detail. He believes that these risks may lead to project failure, and the loss of project failure will be borne by the government. According to this path, project risk will eventually evolve into public risk. Christopher $\mathrm{m}$, Lewis and Ashoka Mody (1998) divided the risks faced by the government into four risks: financial risk, commercial risk, operational risk and event risk. To avoid the related risks, the government must have a reasonable assessment of such risks in the budget and make budget measurement. Norbert portz (2007) proposed that it is very difficult for the private sector to participate in infrastructure projects through the research on the New South Railway Project in Australia. Only when there is a certain understanding of the risk sharing behind the project contract, can great financial risks be avoided. Irwin and Mokdad (2010) emphasized the role of approval procedures, risk assessment and contingent debt reporting in the prevention of PPP government debt risk.

\section{Overview of domestic research}

Domestic scholars have done many researches on PPP model, but few researches on PPP financial risk. In recent years, with the central government and the Ministry of finance gradually paying attention to PPP financial risk, a small amount of research on this aspect has emerged. Therefore, in view of the lack of research on financial risk of PPP model in China, this paper extends the scope of literature review to the research on PPP model of municipal infrastructure.

\subsection{Definition of PPP mode}

Cao Yuanzheng (2002) believed that PPP mode is that the government and the private sector determine the rights and obligations of both parties through signing cooperation contracts, share project risks and social responsibilities, and distribute investment income, the basic forms mainly include operation and maintenance, lease and purchase, BOOB / BT0 and franchise. Jia Kang and Sun Jie (2009) pointed out that PPP mode is a new management mode. By allowing private capital to participate in the supply of public services, we can improve the efficiency of supply and make 
full use of limited resources. PPP mode is not only a financing mode, but also one of many purposes of PPP mode. Ye Xiaosu and Xu Chunmei (2013) put forward the definition suitable for China's PPP, and clarified the "partnership" in PPP and the policy and mechanism innovation ways to promote the application of PPP. Fu University and Lin Fangzhu (2015) defined the scope of "private" in the PPP of public-private partnership, and believed that "private" includes any non-public organization including the private sector, namely the private enterprise and the third sector.

\subsection{Advantages (functions) of PPP mode}

Sun Jie (2005) believes that PPP model has advantages in alleviating public financial pressure, meeting public demand and improving market efficiency. Li Hongjuan (2014) made an in-depth discussion on the motivation and support path of financial support PPP model, and believed that promoting the application of PPP model is conducive to promoting the construction of new urbanization, improving the public service of the government, and establishing a modern financial system.

\subsection{Factors influencing private sector participation in PPP model}

Yuan Jingfeng (2009) conducted a questionnaire survey on the managers of private enterprises, and then conducted a multivariate factor analysis on the results of the questionnaire survey, so as to determine the key factors affecting the willingness of private enterprises to participate in Infrastructure projects of PPP mode. According to Ke Yongjian, Wang Shouqing and Chen Bingquan (2009), government incentive measures in Infrastructure PPP projects mainly include financial subsidies, government assistance to PPP project financing, government guarantee, tax relief, etc.; from the effect comparison of various government incentive measures, tax relief policies have the largest incentive effect on the private sector, while financial subsidies have the smallest incentive effect on the private sector. Ouyang Feng and Zeng Jing (2015) said that investor protection should be strengthened in PPP mode, pointing out that investor protection has a significant positive correlation with the degree of privatization of PPP mode and the amount of project financing; the degree of privatization of PPP mode has a significant negative correlation with the amount of project financing.

\subsection{PPP project investment decision and mode selection}

\subsubsection{PPP project investment decision}

Song Xiaoning, Chen Bin and Wu Mingqin (2014) believed that in the selection of infrastructure supply mode, when there is a complementary relationship between the impact of innovation input in the two stages on operating costs, the traditional government procurement mode is better; when there is an alternative relationship between the impact of innovation input in the two stages on operating costs, the PPP mode is better. Liu Yong, Xiao Zhu and Xu Yelin (2015) believed that psc-ppp comparative method should be used as the standard evaluation method for project approval decision-making of Infrastructure PPP projects.

\subsubsection{PPP project mode selection}

Run Jiangqi (2015) believes that the development of Chinese style PPP will mainly evolve from GSP to PSP, rather than directly copying the PPP mode of western style. Zhan Hui (2014) pointed out that whether service flow, loss flow, cash flow, capital flow and other factors can be converted and the degree of conversion is the key to decide which PPP mode is adopted for infrastructure investment and financing.

\subsection{PPP contract conclusion and renegotiation}

\subsubsection{Public private trust and PPP contract conclusion}

Du Yaling and Yan Peng (2013) pointed out the role of trust in the control of PPP project contracting risk, and put forward the idea of formulating contracting risk control strategy based on the dynamic evolution law of trust in the process of PPP project contracting. Du Yaling, Yin hang, Yin Yilin and Du zechao (2015) used grounded theory to analyze 9 influencing factors of trust in 
PPP project negotiation, which can be divided into three categories: inherent characteristics of both parties, interaction behavior of both parties and psychological contract of both parties. Du Yaling and Yan Peng (2014) conducted an empirical analysis on the formation mechanism of initial trust in PPP projects. They divided the trust in PPP projects into static initial trust formed in prequalification and continuous trust evolving dynamically in the process of contract negotiation and renegotiation, and built a model of the formation mechanism of initial trust in PPP projects.

2.5.2 Renegotiation of PPP contract

Ma sang (2016) used the bargaining game model to analyze the renegotiation of PPP projects, and believed that the proper division of public and private responsibilities, strengthening the supervision of private sector's operating costs and service quality and other methods can promote the sound development of PPP renegotiation.

\subsection{PPP project capital structure}

According to Ye Xiaosu, Yi Pengcheng and Wu Shuxia (2011), PPP project control right is an enterprise control right based on resources, which constitutes the basis influencing the efficiency of public-private cooperation; because of the different structure of control right, it is not only the choice form of public-private cooperation, but also the condition of the rights and obligations of the cooperation subject. Sun Hui and Lu Yanhong (2014) analyzed the factors influencing the allocation of residual control rights by using game theory, and pointed out that the evaluation of the project by both parties, the irreplaceable degree of each party in the investment and the satisfaction of both parties with the expected cooperation income of the project are important factors affecting the allocation of residual control rights.

\subsection{PPP participant relationship and behavior strategy}

Zhang Hui (2015) used game theory to analyze the risk state and game behavior of the government, banks, private institutions and other investors. He believed that commercial banks should not only fully "glue" the three forces of the government, private institutions and banks, but also pay attention to effectively prevent and resolve their own credit risk in the risk game of the investors. Xu Ying (2013) believes that in PPP projects, enterprises should strive for advantageous, dependent, dormant and discretionary stakeholders to become active stakeholders and participate in organizational decision-making, while for dangerous and important stakeholders, they should try to reduce the conflict of interest in the project. Ren Zhitao and Li XiaBing (2014) believed that there were differences and symbiosis between the main behavior characteristics of the government and the private sector in the construction and operation of public infrastructure projects, and then analyzed how to promote the symbiosis behavior, so as to make the efficiency of both public and private parties reach the best.

\subsection{PPP model risk identification, assessment and allocation}

\subsubsection{Risk identification}

Qi Xia, Ke Yongjian and Wang Shouqing (2009) summed up the main risks of China's PPP project based on case research, and believed that the main risk factors were: legal change, project approval delay, decision-making error of government, political opposition, government trustworthiness, force majeure, financing obstacles, insufficient market revenue, project uniqueness, accessory equipment and service provision, market demand change, charge change, corruption, etc. Zhao Ye (2015) thinks that the risk factors in PPP process include: the stability of international and domestic political situation, the change of central government's policy on non-public assets, the change of exchange rate policy, national legal policy, the suspension of projects in case of emergencies, the willingness of local government, the ability of local government, the continuity of local government and policy, the attitude of the people towards the project, and whether there is rent-seeking behavior.

\subsubsection{Risk assessment}

He Shoukui and Fu Hongyuan (2006) adopted the comprehensive evaluation method to determine the project risk and income distribution mode of the government and the private sector in the 
projects of PPP model. He Yabo, Xu Bing and Chang Xiufeng (2016) determined the weight of each risk factor in PPP project through the improved entropy weight method, and evaluated the risk of urban rail transit PPP project using the grey correlation model. Wang Jianbo, Zhao Jia and Niu fayang (2016) used the method of Choquet fuzzy integral to evaluate the financing risk of urban rail PPP project.

\subsubsection{Risk allocation}

Lin biaowen (2013) proposed four risk sharing principles which PPP project should follow: symmetry principle, optimality principle, upper limit principle and dynamic principle. Zhou Heping (2014) believed that whether the risk sharing of PPP project among the participants is fair or not, to a large extent, determines whether the PPP project can operate successfully. When unexpected risks appear in the project, the government and franchisee need to adjust the original risk sharing scheme in time. Li Yan (2015) used the bargaining game theory under the condition of incomplete information to construct the risk sharing model of PPP project with the government bidding first and the risk sharing model of PPP project with the private bidding first, so as to reasonably determine the risk share of the government and the capital.

\subsection{Financial risk of PPP model}

Ji Fuxing (2010) believes that the abuse of PPP model will lead to financial illusion, risk concealment and risk mismatch. For PPP model, we should focus on building an effective risk sharing and incentive compatibility mechanism, and integrate its responsibilities into the framework of medium and long-term financial planning, and place it in the asset and liability management system of accrual basis. Zeng Xiaohui and Zhan Qilin (2013) thought that the government's various implicit or contingent liability problems would make the government bear more financial risks, and adopted the quantitative analysis method to obtain the influence weight of various factors of financial risks, and found that the government guarantee is the most important factor of financial risks in PPP mode. Zhou Xiaofu (2013) proposed that government guarantee is the direct cause of financial risk, and the separation of ownership in legal form and economic essence is the root of financial risk in the current PPP model. Bai Lupan and Wang Chuncheng (2014) pointed out the hidden risks of public debt management in PPP mode, namely, the legal guarantee responsibility beyond the contract undertaken by the government, the expenditure responsibility based on the product demand guarantee for PPP projects, and the government's relief responsibility for PPP projects. Wen Laicheng, Liu Hongfang and Peng Yu (2015) pointed out that due to the lack of legal and moral constraints, the government has to bear more financial risks in the PPP model. Fan Yixia (2017) pointed out that when the risks are not fully considered in the preparation of the budget, PPP mode will appear "Fiscal Illusion", and there is a risk that the social capital cannot be paid in full. Therefore, it is necessary to clarify the responsibilities of the government such as assets, expenditure and repayment obligations based on the separation of asset management rights and operation rights, so as to share the risks reasonably. Liu intelligent (2017) classified the failure cases in the development process of PPP in China, providing ideas for the design of PPP system and financial risk prevention. Ma Jintao and Li Xin (2017) summed up the Enlightenment on the management of PPP government debt risk in China by referring to the management framework established by Chile, Peru, South Africa, Turkey and other countries for PPP debt risk. Chen Shaoqiang (2018) believes that the basic concept of PPP financial risk management in China is flow management, and there are some defects in PPP financial risk flow management mode. It is suggested to introduce stock management on the basis of flow management to realize the effective combination of flow management and stock management.

\section{Evaluation of existing research}

Generally speaking, the research on PPP mode of domestic scholars is very rich, and mainly focus on the connotation, function, participants and their relationship, project governance mechanism, benefit distribution mechanism, risk identification and evaluation, project investment decision-making and other aspects of PPP mode. As PPP mode has not been widely concerned by 
domestic scholars for a long time, most of the researches on PPP mode are conducted from the perspective of attracting private sector to participate in the investment and construction of urban infrastructure and transportation infrastructure, so as to relieve the financial pressure of the government. In fact, the purpose of implementing PPP mode is far more than that. The significance of PPP mode is not only reflected in inciting more social capital by limited government investment through a certain operating mechanism, but also reflected in helping the government to improve the level and efficiency of infrastructure projects causing by advanced management concepts, advanced technical means and modern scientific corporate governance mechanism of the private sector. Comparing with the researches on PPP mode at home and abroad, we can find that most of the researches involved the risk issues of PPP mode more or less. However, after we summarize existing research results, we can see that the existing research is not systematic: on the one hand, the research on the overall risk of PPP project and related evaluation is not very deep; on the other hand, scholars have only made a general classification and analysis of the risk of PPP mode to a certain extent, the research on specific risk types and the causes behind the risks are insufficient at present.

\section{Summary}

The future research of infrastructure PPP mode should focus on the following aspects: Firstly, the applicability analysis of PPP mode in China's special national conditions is very important, especially the systematic and in-depth consideration of the source, formation mechanism and transmission mechanism of financial risk of PPP mode. Secondly, we should strengthen the research on the contract management theory and practice of PPP project under the condition of socialist market economy in China. Thirdly, the scientific design of equity distribution mechanism, income distribution mechanism and risk distribution mechanism in the aspect of mechanism construction of PPP mode cooperation are core issues of future research.

\section{Acknowledgment}

This research was financially supported by the Doctoral Science Research Fund Project of WuHan Business University "Research on the financial risk identification, measurement and prevention of PPP model of municipal infrastructure" (Grant NO. 2018KB010).

\section{References}

[1] Wu Miao, and Zhang Jingfu, review of risk management research on PPP projects, Journal of Wuhan University of science and Technology (SOCIAL SCIENCE EDITION), vol.1, pp. 39-47, 2019.

[2] Ye Xiaosu, and Xu Chunmei, a review of the research on public private partnership (PPP) model of public projects in China, Soft science, vol. 6, pp. 6-9,2013.

[3] Wu Haixi, Dai Dashuang, and Liu Ning, review of BOT / PPP pattern recognition and selection, Technology and economy, vol. 2, pp. 68-73,2010.

[4] Bai Wenjie, Research on financial risk of PPP model, China Academy of financial Sciences, master's thesis ,2016.

[5] Chen Shaoqiang, Research on improving PPP financial risk management-Based on the perspective of combination of flow management and stock management, Journal of Central University of Finance and economics, vol. 12, pp.3-13,2018. 